\title{
Introduction
}

\section{EDUCATION IN HEART}

7 mark the new millennium Heart has decided, with the support of the British Cardiac Society and BMJ Publishing Group, to recognise and develop the potential role for the journal in the important arena of postgraduate education. This issue contains the first of a series of articles that will extend over three years, appearing at the end of each issue of the journal under the heading "Education in Heart". We have, perhaps ambitiously, two objectives.

The first is the worldwide need for educational material that can be used by established consultants in cardiovascular medicine as a means of remaining up to date with both scientific and clinical aspects of their speciality. The articles commissioned in the Education in Heart section will address this need. They are different from editorials in the journal, which are designed either to comment on, and inform the readership about subjects of primary research interest, and may from time to time link to articles published in the journal. In this respect, the editorials should broadly reflect the papers submitted to the journal. The scope of Education in Heart is designed to cover the field of knowledge that might usefully inform established cardiologists.

In addition, we hope they will provide a useful resource for cardiologists in training, offering an authoritative exposition of the broad range of knowledge that trainees might reasonably wish to attain.

In aiming to meet these objectives, the section editors of Education in Heart have spent much time in planning and discussing the range of articles that have been commissioned. We have taken particular care to seek authorship from a broad geographical base, which we hope will appeal to our international readership as well as members of the British Cardiac Society.

We propose to publish educationally valuable comments and correspondence on the Heart web site (www.heartinl.com) and, where appropriate, will draft reviews of these comments for publication in the pages of the journal. Comments, suggestions, points of agreement, emphasis or disagreement are therefore welcome and should be sent by email to heartjournal@bmjgroup.com.

As the articles appear over the next three years, the commitment and inspiration of the section editors will become clear and I am extremely grateful to them, as well as to the project manager, Mr John Weller, for all their hard work and excellent advice in developing this series.

PETER MILLS SERIES EDITOR

Section editors

Michael J Davies (cardiomyopathy), Chris Davidson (general cardiology), John L Gibbs (congenital heart disease), Roger Hall (valve disease), David Lefroy (heart failure, imaging, electrophysiology), Janet M McComb (electrophysiology), R Gordon Murray (coronary disease) 